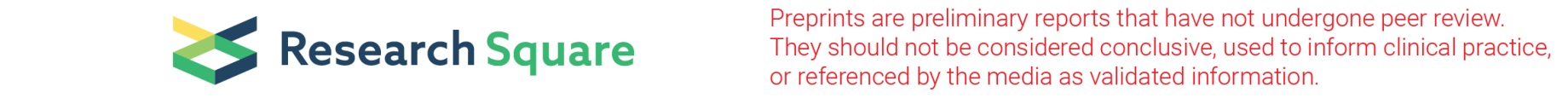

\title{
Examining Diffusion and Convergence Processes of Three Road Safety Policies, 1964-2015
}

Jose Nazif-Munoz ( $\square$ jose.ignacio.nazif-munoz@usherbrooke.ca )

Université de Sherbrooke https://orcid.org/0000-0002-8944-5182

Axel van den Berg

McGill University

Amélie Quesnel-Vallée

McGill University

Article

Keywords: public policies, longitudinal data, global convergence process, elective affinities, fractured convergence processes.

Posted Date: October 8th, 2021

DOI: https://doi.org/10.21203/rs.3.rs-770314/v1

License: (1) This work is licensed under a Creative Commons Attribution 4.0 International License. Read Full License

Version of Record: A version of this preprint was published at Humanities \& Social Sciences Communications on November 16th, 2021. See the published version at https://doi.org/10.1057/s41599-021-00954-z. 


\section{Abstract}

Global convergence of public policies has been regarded as a defining feature of the late twentieth century. This study explores the generalizability of this thesis for three road safety measures: i) road safety agencies; ii) child restraint laws; and iii) mandatory use of daytime running lights. We analyze cross-national longitudinal data using survival analysis for the years 1964-2015 in 181 countries. Our first main finding is that only child restraint laws have globally converged; in contrast, the other two policies exhibit a fractured global convergence process, likely as the result of competing international and national forces. This finding may reflect the lack of necessary conditions, at the regional and national levels, required to accelerate the spread of policies globally, adding further nuance to the global convergence thesis. A second finding is that mechanisms of policy adoption, such as imitation/learning and competition, rather than coercion, explain more consistently global and regional convergence outcomes in the road safety realm. This finding reinforces the idea of specific elective affinities, when explaining why the diffusion of policies may or not result in convergence. Lastly, by recognizing fractured convergence processes, our results call for revisiting the global convergence thesis and reintegrating more consistently regional analyses into policy diffusion and convergence studies.

\section{Introduction}

Political scientists, economists, international relations' experts, and sociologists have done a great deal of research on the convergence of public policies. In this growing area of research one finds analyses which have focused on the diffusion and convergence of health policies (Iriart, Merhy and Waitzkin, 2001; Luke and Cotts Watkins, 2002; Gilardi, Füglister and Luyet, 2009; Wipfli, Fujimoto and Valente, 2010), economic policies (Brooks, 2005; Weyland, 2005; Lee and Strang, 2006; Kogut and Macpherson, 2008, 2011), and policies such as the adoption of democratic institutions, human rights laws, and laws against terrorism (Hafner-Burton and Tsutsui, 2005; Shor, 2008; Skrede Gleditsch and Ward, 2008; Pegram, 2010; Shor et al., 2014). One of the main conclusions of these studies has been a strong trend towards policy convergence at the global level.

In this article, we examine the generalizability of the global policy convergence thesis and revisit an analytical framework applied to examine the mechanisms that should facilitate or delay policy convergence. For this, we study three road safety policies i) road safety agencies (RSA); ii) child restraint laws (CRL); and iii) daytime running lights (DRL). Our study contributes to four research areas in the study of the global convergence of public policies. First, studies of global convergence of public policies (Marsh and Sharman, 2009) tend to analyze case studies, which may lead to a bias in favour of the generalizability of the convergence thesis. In contrast, our research follows in the footsteps of a body of cross-national studies. Second, few studies have compared convergence processes of different public policies across countries. Wotipka and Tsutsui (2008) analyzed simultaneously seven human rights international treaties; Koo and Ramírez (2009) studied the adoption of two national human rights institutions; Frank, Camp and Boutcher (2010) examined the convergence of criminal regulation of rape, adultery, sodomy, and child sexual abuse; and Shor and colleagues (Shor et al., 2014) applied a cross-sectional analysis to examine four practices of state repression. Like these studies, we simultaneously analyze the effects of three different policies, which share the objective of decreasing traffic injuries and fatalities. That is, we analyze the effect of similar forces on different outcomes, which allows us to identify more clearly when the convergence thesis can be accepted, rejected, or reformulated. Third, to examine the global policy convergence thesis more rigorously, we argue that it is important to introduce similar conditions of falsifiability when studying the duration of policy convergence processes. In other words, the time span to compare the possibility that similar policies can converge should be relatively constant. Last, specific works on road safety policy diffusion (Nazif-Muñoz, 2015; Hyder et al., 2017; Flannigan and Khayesi, 2021) did not consider mechanisms of convergence, and therefore little in known on the conditions under which different road safety policies may or not be globally adopted. Thus, to uniformly test the thesis of global policy convergence and examine its mechanisms, we have selected policies that at least 40 years of existence. While it is uncertain in which country the first RSA was established, it is in the 1960s, when these institutions were first observed: in Norway, the Norwegian Public Roads Administration was funded in 1864, however legal changes suggest that roles as RSA began in 1964 (Samferdselsdepartementet, 1964; The Norwegian Public Roads Administration, 2021), the United Kingdom in 1965, and in Denmark and the United States in 1966. The first CRL was simultaneously enacted in Belgium and Denmark in 1975, and the first mandatory DRL norm in Finland in 1972.

\subsection{Why road safety policies?}

From 1990 to 2010, the fraction of global deaths due to injuries increased from 8.8-9.6\% of global deaths (Lozano et al., 2012). In 2020, road injuries were the second biggest cause of death among males aged 15-49 at the global level, accounting for $10.9 \%$ of the deaths in that age group. (United Nations, 2021). These trends are unlikely to abate, as projections indicate that road traffic crashes will rise from the seventh leading cause of death in 2020 to the fifth in 2030, with the burden unequally distributed globally, as poor and middle-income countries will see crashes match HIV/AIDS as a cause of death (World Health Organization, 2019). This state of affairs triggered a strong global response led by international organizations providing aid and guidance to different countries (Ameratunga, Hijar and Norton, 2006; 
Sharma, 2008; Rosenberg et al., 2010; Bliss and Breen, 2012). In 2004, the WHO, in conjunction with the WB, launched the World report on road traffic injury prevention (World Health Organization, 2004) through which a set of policies-based on scientific publications and advice provided by road safety experts-were chosen and promoted to tackle the burden of road traffic injuries and fatalities. After the launching of this report, the WHO led a campaign aimed at reducing traffic fatalities and injuries across the world. The importance of road safety globally was ultimately acknowledged in the United Nations' Sustainable Development Goals, under the 'Good Health' and 'Sustainable Cities and Communities' goals (United Nations, 2016).

\subsection{Which road safety policies?}

We study the following road safety policies:

a) Road safety agencies. Lacking the appropriate institutional infrastructure can impede the curbing of traffic injuries and fatalities. According to various WHO reports, implementing an RSA is a first important step towards attaining these objectives (World Health Organization 2008, 2013). More particularly, this type of institution becomes necessary because road safety work involves coordinating representatives of different governmental (such as health, transport, public works or police) and private sectors (highway construction, or automobile and alcohol industries). However, the WHO recognizes that various institutional forms have been developed to decrease the occurrence of traffic injuries and fatalities. That is, an RSA can be a designated stand-alone bureau, a committee or council representing several different government bodies, or it can be a part of the Ministry of Health, Transport or Security. Furthermore, these agencies can perform different functions such as: coordinate the activities of different stakeholders involved in road safety policy making, introduce road safety legislation, monitor and assess the implementation of road safety policies, and set road traffic fatality reduction goals.

b) Child restraints laws. Restraints in cars are intended to keep children in their place on the seat so that in the event of sudden braking or vehicle crash children are not thrown against the interior or out of the car. As such $\mathrm{CRL}$ are designed to reduce the number of injured children by assuring that a higher proportion of them are secured in the vehicles. Meta-analysis led by Elvik and Vaa (2009) suggests that the effect of mandatory wearing of child restraints in cars decreased the number of children injured in cars by $15 \%$.

c) Daytime running lights. Many traffic crashes happen because road users do not notice each other in time or do not notice each other at all. This situation can emerge in darkness as well as in daylight. Vehicle visibility is therefore one of the factors affecting the number of traffic crashes. Use of DRL in all light conditions is intended to reduce the number of multi-vehicle crashes by increasing the cars' visibility and making them easier to notice in good time. Meta-analyses led the European Transport Safety Council (2006) have suggested that DRL reduce multi-vehicle crashes by around $6 \%$. However no clear agreement regarding the overall effectiveness of this measure is currently present in the literature since some anomalies have been observed in various studies (Elvik, 2013).

\section{Global Convergence Outcomes And Mechanisms Of Policy Convergence.}

When analyzing convergence of policies, it is important to analytically distinguish between convergence as an outcome (i.e., global convergence, regional convergence and unintended convergence), and the mechanisms (i.e., imitation/learning, coercion, and competition) that may produce or delay convergence.

\subsection{Convergence outcomes}

a) Global convergence. An important number of scholars has reached the conclusion that, due to the presence of active international actors and communities (i.e. United Nations-related organizations), countries have tended more and more to adopt very similar policies (Harvey, 1989; Meyer et al., 1997; Martinneli, 2005). That is, policies across the world grow more alike in terms of their structures, processes, and performances. This phenomenon has been labeled global policy convergence (Drezner, 2001). In the realm of road safety, it could be expected to observe global convergence because various international agreements and international actors have purposely promoted road safety policies across the world. This has occurred through for instance the signing of international instruments, such as the Geneva Convention or the "Agreement concerning the Adoption of Uniform Technical Prescriptions for Wheeled Vehicles, Equipment and Parts which can be fitted and/or be used on Wheeled Vehicles and the Conditions for Reciprocal Recognition of Approvals Granted on the Basis of these Prescriptions" (AAUTPV) -; and the exchange of knowledge among scholars from different countries in forums such as the Association for the Advancement of Automotive Medicine-in which the assessment of road safety policies has been a common practice of road safety scholars.

b) Regional convergence. Rather than observing global policy convergence, other authors have suggested that policy converge may occur only regionally (Rompuy, 2021). This type of convergence arises because existent regional institutions or arrangements facilitate policy exchange across countries within regions systematically. In road safety, regional convergence may have occurred in Europe, or Latin America 
and the Caribbean (LAC) because of two different processes. In 1992, in Europe, the European Traffic Safety Council was created. The objective of this organization is to contribute to the reduction of traffic injuries and fatalities across this continent by promoting evidencebased road safety policies. Currently this type of institutional arrangement is absent in other world-regions. From 2004 onwards in LAC, several international organizations, such as the Pan American Health Organization, the Economic Commission for Latin America and the Caribbean, and the Inter-American Development, worked closely with health and transport authorities to promote road safety policies in this region. This work was aligned with the road safety global campaign led by the WHO, the WB and other international actors (World Health Organization, 2013).

c) Unintended convergence. A third convergence outcome is one in which countries adopt the same policy despite the absence of global or regional forces conducive to this outcome. Instead of following international influences these countries may be affected by similar national dilemmas and thus their solutions unintendedly converge. There are at least three factors that can facilitate or inhibit convergence in road safety. First, given that population size is positively associated with traffic crashes and fatalities, countries with larger populations may be more inclined to adopt these policies to decrease these transport externalities. Second, countries in which political violence is high may not consider road safety to be a national priority or lack the capacity to tackle it. Lastly, one could expect that countries in which there are explicit problems of road visibility, particularly during winter seasons, such as in Nordic countries (Koornstra, 1993), will be more likely to implement DRL.

\subsection{Mechanisms of policy convergence}

Several authors have identified learning/imitation, coercion and competition as some of the main mechanisms that explain how policy convergence is facilitated or delayed either globally or regionally (Lee and Strang, 2006; Dobbin, Simmons and Garrett, 2007; Simmons, Dobbin and Garrett, 2008; Marsh and Sharman, 2009).

a) Learning/imitation. Various scholars highlight the predominance of world-culture in the process of policy convergence. Meyer et al. (Meyer et al., 1997) state that countries are likely to imitate or learn policies and adopt them when these are in vogue or legitimized. Policies whose goals are socioeconomic development, citizen rights, and civil international relations, among others, are commonly referred to as legitimate, as they are based on values such as democracy, freedom, equality and human rights (Meyer et al., 1997). Two sources favor policy convergence through imitation/learning: i) international communities of policy makers and/or experts, and ii) NGOs with links to international alliances. These groups usually promote policies which have been proven, theoretically or empirically, effective, and provide "policy makers [with] rationales for adopting [them at the national level]" (Strang and Meyer, 1993; Dobbin, Simmons and Garrett, 2007). There are two elements that may coincide with the convergence of road safety policies via the imitation/learning mechanism. First, from 2004 onwards, the WHO and the WB, as representatives of communities of experts, led a campaign to promote road safety practices at the country level. Second, the Global Alliance of NGOs for Road Safety has actively interacted with national NGOs to foster road safety policies in their territories.

b) Coercion. The work by Wallerstein has been paramount to understand how this mechanism operates (Wallerstein, 1974, 1979, 2004, 2011). Wallerstein sustains that economic systems which favor the 'ceaseless accumulation of capital' (Wallerstein, 1979) is what determines convergence of policies. Thus, countries may adopt policies that promote the interest of certain private industries, or conversely may reject policies that challenge the increment of profit. The exporter automobile industry is a good arena to test Wallerstein's thesis in the realm of road safety. Mohan and Roberts (Mohan and Roberts, 2001) have argued in fact that the formation of road safety policies may be affected by the interests of car manufacturers. They specifically note that this industry has been an important stakeholder of the Global Road Safety Partnership (GRSP) alliance which has played a prominent role in road safety policy development since 1999. Mohan and Roberts (50) suggest that car companies, through their participation in the GRSP rejected road safety measures that increase the costs of cars manufacturing. Roberts et al. (Roberts, Wentz and Edwards, 2006) and Roberts (Roberts, 2007) provide evidence that international organizations which were supported by the car industry were unlikely to promote measures that negatively affected their commercial interests. While DRL is a safety requirement which the automobile industry would need to accommodate, RSAs may also represent a threat to the car industry, because the introduction of vehicle safety standards is likely to be one objective of these agencies. Both measures could thus represent potential increases for the automobile manufacturing costs. Following Wallerstein, one could expect thus that the car industry would resist the diffusion of these two policies.

c) Competition. This mechanism works as follows: when two countries (countries A and B) trade with a third one (country C), country A can obtain competitive advantage over country $B$ by adopting a new policy, if country $C$ prefers to acquire products which are manufactured following the new policy. This new scenario will have an impact on country $B$, since the most probably way to remain competitive and avoid exclusion from the trade, is by adopting the new policy $(45,56)$. International trades between both vehicle-exporting and vehicle-importing countries, thus become relevant. If some vehicle-exporting countries introduce and implement in their production lines national safety 
regulations that prevent other vehicle-exporting countries from participating in their market, the remaining vehicle-exporting countries will adjust their safety practices to remain competitive and therefore would promote the diffusion of said policies in their own territories.

\section{Methodology}

\subsection{Data}

We compiled and analyzed data for 181 countries between 1964 and 2015 . Details of sources are described in supplementary material (Tables S.1, S.2, S.3, and S.4).

\subsection{Dependent variables}

We analyzed the convergence of RSA, CRL and DRL. Information to establish the year in which each country implemented each policy was systematically gathered and coded according to a standardized scheme from the WHO reports on road safety (World Health Organization, 2004, 2010, 2013, 2019), national traffic laws, peer-reviewed journals, governmental and international organization reports, and personal communication via email with road safety country representatives. The WHO reports identify whether each country has an RSA and CRL. The WHO applies a specific methodology to collect reliable information per country. Since 2010 , it biannually sends a questionnaire that must be completed by five representatives of each country, and for this information to be made public, these national representatives must agree on their responses as well as provide official documents, such as traffic laws or any other legal instrument, stating that the information is accurate. Then from each available source, we extracted, and when necessary translated, the dates when the RSAs were created, and the norms which regulated CRL and DRL use in traffic laws. In reference to the RSAs, we identified in the WHO reports the specific names of each agency and proceeded to locate their institutional websites and other reports to find the years in which these organizations were created. Regarding CRL, we looked at the seat-belts' sub-section, and for DRL, we focused on the use of lights' sub-section We also located definitions of the concepts "beginning of sunlight" or "end of sunlight" to determine when the use of lights was mandatory. Similarly, we proceeded to identify when these laws were for the first time enacted after evidence of policy adoption was confirmed. In Table S.5 (supplementary material) we present the years of enactment for each policy for 181 independent countries. Coverage for RSAs was $97 \%$, for CRL $98 \%$, and for DRL 83\%. We treated policy convergence as an event that occurred, and absence of convergence when the policy had not been adopted. The dependent variables were thus: i) 'Time to adopt a RSA'; ii) 'Time to adopt CRL'; and iii) 'Time to adopt DRL'.

\subsection{Independent variables}

\section{a. Types of convergence}

Global convergence. We explore whether global convergence has been reached, by using the shape parameter $\rho$ of the Weibull function of the survival analysis models as we describe below. In reporting the results, following Kogut and Macpherson (Kogut and Macpherson, 2011), we also call this shape parameter "time," as its sign provides information on whether baseline adoption increases or slows during the observed period. A declining hazard rate can represent statistical bias arising from unobserved heterogeneity, meaning that conditions to accept the global convergence thesis are not met (Kogut and Macpherson, 2011). For the thesis of convergence to be supported, the parameter $\rho$ should increase significantly.

We also use two international treaties to observe factors that can be associated with global policy convergence: the "Geneva Convention on Road Traffic", and the AAUTPV. International treaties, understood as variables that represent global forces, have been used to predict the convergence of policies, particularly in the realm of human rights (Cole, 2012). The Geneva Convention on Road Traffic was designed to promote the development of traffic safety by establishing certain uniform rules. Information of which countries signed the convention and the date of the signature is provided by the United Nations (United Nations, 1995). This variable was dichotomous in which ' 0 ' corresponds to the period before the signature, and represents not having signed the convention, and ' 1 ' the period after having signed the convention, representing whether a country has agreed to adhere to road safety policy recommendations. The AAUTPV was promoted to establish rules of reciprocity between signing countries. This agreement set the conditions to discuss the uniform provisions concerning $\mathrm{CRL}$ as well as DRL. Information of which countries signed the agreement and at what date is provided by the United Nations (67). Like the Geneva Convention, this variable was dichotomous in which ' 0 ' corresponds to the period before the signature and represents not having signed the agreement, and ' 1 ' the period after having signed the agreement, representing whether a country has been more inclined to adopt CRL and DRL.

Regional convergence. To determine whether a regional convergence has occured, we use the $\rho$ of the Weibull function of the survival analysis when restricting the analysis for Europe and LAC, respectively. For Europe, we also consider the Creation of the European Transport 
Safety Council. This variable was set to be dichotomous, with '0', corresponding to the period before 1993, representing the absence of this institution, and ' 1 ', the period of 1993 onwards, representing the time period following the launch of this institution. Results for Africa, Asia and the Pacific, and Western Asia are available in supplementary material (Table S.6).

Unintended convergence. To assess unintended convergence outcomes, we assess three variables. Population. Population has been obtained from the WB (World Bank, 2020). We logged this variable to correct for its skewed distribution. Political violence. This variable is defined by the systematic and sustained use of lethal violence by organized groups that result in at least 500 directly related deaths over the course of the episode. Each episode is designated to span a certain number of years and judged to have been of a certain, general "magnitude of societal-systemic impact". An eleven-point scale, 0-10 gathered from the Center for Systemic Peace was used (Marshall, 2021). Average yearly total number of hours of bright sunshine. According to the World Meteorological Organization (WMO), bright sunshine duration during a given period is defined as the sum of the sub-period for which the direct solar irradiance exceeds $120 \mathrm{Wm}^{-2}$. Data were gathered from the WMO ((Organization (WMO) and World Meteorological Organization (WMO), 2018).

\section{b. Mechanisms of convergence}

Variables representing mechanisms of convergence were introduced to examine if policies were or not adopted. These were divided into three: imitation/learning, coercion, and competition.

Imitation/learning. World Health Organization road safety global campaign. In 2004, this UN body launched a global campaign to promote the implementation of road safety measures to reduce the toll of traffic fatality and injury rates across the world (World Health Organization, 2010, 2013). From 2004 until the present, this organization has written a series of reports and carried out several world and regional forums to endorse a series of road safety best practices. This variable was dichotomous with ' 0 ' corresponding to the period before 2004 , and representing the absence of the global campaign, and ' 1 ' representing the period of 2004 onwards, following the launching and dissemination of the global campaign.

Imitation/learning. Existence of road safety NGOs. The presence of a road safety NGO in each country represents whether a country has this type of institution. Information was obtained from the Global Alliance for NGOs for Road Safety (Global Alliance for NGOs for road safety, 2020). This variable was dichotomous, with '0' corresponding to countries without membership to the Global Alliance for NGOs for Road Safety, and ' 1 ' representing countries with membership.

Coercion. Type of importer-exporter vehicle country. Three categories were used to classify a country within the vehicle global trade market: i) 'Vehicle-importer country, was a country which did not export any type of vehicle; ii) 'Vehicle-importer-exporter country, was a country in which its vehicle importation trade value was higher than its exportation trade value; and iii) 'Vehicle-exporter country was a country where the vehicle exportation trade value was higher than its importation trade value. Information was gathered from the United Nations Commodity Trade Statistics Database (United Nations, 2020). To determine the category of each country we added up its total amount of vehicle exports trade value and compared it to its total amount of imports vehicle trade value. This was applied for the period in which data for the country was available.

Competition. Type of importer-exporter vehicle country. We use the same categories and data to assess the coercion mechanism, but with an inverse result, namely that Vehicle-exporter countries are more likely to adopt DRL and accept RSA.

\subsection{Control variables}

Gross Domestic Product. It is necessary to take into account a nation's level of development in order to make sure that any effects discovered are independent of a nation's level of wealth, particularly since economic development may increase a nation's ability to tackle road safety challenges (Kopits and Cropper, 2003; Sze, Wong and Lee, 2014). We employ a measure of gross domestic product (GDP) per capita at purchasing power parity for 2000 US\$. These data have been obtained from the WB (World Bank, 2020). We log these data because of their skewed distribution.

Urbanization. We also include the percent of the population living in urban areas in the analysis (percent urban). These percentages have been obtained from the WB (70).

Existence of an RSA. This indicates whether a country has this type of institution. This variable was constructed as explained above, and was used to assess CRL and DRL.

\subsection{Statistical Method}


To obtain valid estimates to test the convergence thesis and the mechanisms of global diffusion, we employ survival analysis. This method allows explaining events occurring to countries over a specified period (Brandon Tuma, 1984; STRANG, 1991; Jenkins, 2005; Cleves et al., 2008). Survival analysis has been used for various types of events ranging from decolonization (Strang, 1994) to policy adoption (True and Mintrom, 2001; Murillo and Martínez-Gallardo, 2007; Wotipka and Ramirez, 2008; Zeveleva and Nazif-Munoz, 2021). We use the Weibull hazard function since its $\rho$ value can be used to interpret whether policy adoption significantly increases during the observed period, and thus leads to policy convergence.

It is important to notice that since outcomes could be a result of modeling countries as if they had been equally exposed to the same time risk, we defined the onset of risk depending on when the country had acquired national independence. However, if the country had obtained independence before the year in which the first policy was enacted, its exposure to road safety policy adoption started in the year in which the policy was enacted for the first time. Information about countries' independence was obtained from the CIA's World Factbook (Central IntelligenceAgency, 2011). Under this modeling, Norway, Belgium, Denmark and Finland were not part of the analysis of the diffusion of RSA, $\mathrm{CRL}$ and $\mathrm{DRL}$, since they were the pioneers of each policy respectively.

Furthermore, since unobserved heterogeneity could also arise from road safety information that countries share due to their regional closeness, implying that unobserved processes could bias the results of the parameters (Cleves et al., 2008), we adjust the precision of the estimates for their adoption time rates in reference to 22 regional clusters based on the United Nations geoscheme (please see in Supplementary material Table S.8 the regional cluster list with the countries). In other words, each regional cluster is assigned a random effect-whose distribution does not depend on the observed variables - to model the potential impact of road safety information exchange among countries within each cluster.

\section{Results}

Figure 1 plots the cumulative number of the national adoptions of these road safety policies over time. By 2015, more than 125 national RSAs had been established, 90 CRLs were enacted, and 40 DRL laws were approved across the world. Table S.1 reports the descriptive statistics of both control and independent variables.

Table 1 reports the structural parameter $\rho$ for each policy at the global level. We observe that for RSAs (Models 1 and 2) the structural parameters time $(\rho)$ capture increases of $1.44(($ Standard error) $($ s.e. $)=0.49)$ and $1.38($ s.e. $=0.46)$ ), indicating that the adoption of this measure has steadily risen across countries and time (as Figure 1 depicts). However, its level of statistical significance suggests that the likelihood to implement RSAs is not exclusively tied to global forces. This is corroborated when we observe that international treaties are not associated with the creation of RSAs across the world. On the other hand, the establishment of RSAs may be a case of an unintended convergence. This can be examined after analyzing population and political violence variables. In Models 1 and 2, population is significantly associated with RSA, and in Model 2, we observe that major episodes of political violence delay RSA convergence. Regarding the mechanisms, we observe that the rate of RSA implementation increases significantly after the global campaign led by the WHO was launched and whether a road safety NGO is present. Lastly, there is evidence to support the competition mechanism rather than the 'coercion' one, because 'Vehicle importer-exporter' countries are more likely to enact RSAs than 'Vehicle importer' ones.

Unlike RSAs, we observe for the case of CRL (Model 3) a significant increase over time in adoption across countries (1.38 (s.e. $=0.15)$ ). This parameter suggests that worldwide forces have shaped a convergence outcome as the global convergence thesis states. This is confirmed when we consider the two global variables (Geneva Convention on Road Traffic and the AAUTPV). We notice also that following the launch of the WHO's global campaign, the adoption of CRL increases significantly. In Model 4 we observe a similar tendency, even if the parameter estimate of this model is slightly lower $(1.28($ s.e. $=0.24)$ ). In other words, neither pure independent national decision-making processes (i.e., enactment of an RSA) nor national dynamics (i.e., a political violence) are sufficient to delay the global convergence of this policy.

Regarding the convergence of DRL, we observe in Model 5 that the structural parameter is significant but lower than $1(0.75($ s.e. $=0.13)$ ), which suggests that forces representing a global trend are weak. However, when the RSA variable is introduced (Model 6), we observe a slight increase in this parameter $(0.78($ s.e. $=0.14))$ as well as in the parameter representing the AAUTPV, confirming that both global and national dynamics may be in place when explaining the adoption rate of this policy. Further, these two models present evidence that supports two types of mechanisms of convergence: imitation/learning and competition. Regarding the mechanism of competition, one observes that 'Exporter-vehicle countries' and 'Importer-exporter vehicle countries' are more likely to adopt DRL than 'Importer-vehicle countries.' 
Table 1

Global convergence of RSA, CRL and DRL

\begin{tabular}{|c|c|c|c|c|c|c|}
\hline & $\begin{array}{l}\text { RSA } \\
\text { (Model 1) }\end{array}$ & $\begin{array}{l}\text { RSA } \\
\text { (Model 2) }\end{array}$ & $\begin{array}{l}\text { CRL } \\
\text { (Model 3) }\end{array}$ & $\begin{array}{l}\text { CRL } \\
\text { (Model 4) }\end{array}$ & $\begin{array}{l}\text { DRL } \\
\text { (Model 5) }\end{array}$ & $\begin{array}{l}\text { DRL } \\
\text { (Model 6) }\end{array}$ \\
\hline \multicolumn{7}{|l|}{ Global convergence } \\
\hline \multirow[t]{2}{*}{ Geneva Convention on Road Traffic } & 1.24 & 1.17 & $1.40 *$ & 1.10 & 1.69 & 1.75 \\
\hline & $(0.22)$ & $(0.22)$ & $(0.27)$ & $(0.20)$ & $(0.94)$ & $(0.77)$ \\
\hline \multirow[t]{2}{*}{ AAUTPV } & 1.05 & 0.95 & $3.38 * \star *$ & $3.13^{* * *}$ & $3.98 * * *$ & $4.32 * \star \star$ \\
\hline & $(0.35)$ & $(0.30)$ & $(1.07)$ & $(0.99)$ & $(1.73)$ & $(2.44)$ \\
\hline \multicolumn{7}{|l|}{ Regional convergence } \\
\hline \multirow[t]{2}{*}{ Creation of the European Transport Safety Council } & - & 一 & - & - & 1.24 & 1.25 \\
\hline & & & & & $(1.19)$ & $(1.10)$ \\
\hline \multicolumn{7}{|l|}{ Unintended convergence } \\
\hline \multirow[t]{2}{*}{ Population (In) } & $1.14^{* \star}$ & $1.15^{*}$ & 1.02 & 1.03 & $0.69 * *$ & $0.61 * * *$ \\
\hline & $(0.07)$ & $(0.08)$ & $(0.08)$ & $(0.09)$ & $(0.12)$ & $(0.09)$ \\
\hline \multirow[t]{2}{*}{ Political violence } & - & $0.90 *$ & - & $0.77 * *$ & - & - \\
\hline & & $(0.05)$ & & $(0.09)$ & & \\
\hline \multirow[t]{2}{*}{ Average yearly total number of hours of bright sunshine } & - & - & - & - & 0.84 & 0.89 \\
\hline & & & & & $(0.36)$ & $(0.33)$ \\
\hline \multicolumn{7}{|l|}{ Mechanisms of diffusion } \\
\hline \multicolumn{7}{|l|}{ Imitation/learning } \\
\hline \multirow[t]{2}{*}{ World Health Organization road safety global campaign } & $3.44 * * *$ & $3.61 * * *$ & $2.64 * * *$ & $2.54^{* *}$ & $5.28 * *$ & $3.78 * * *$ \\
\hline & $(0.93)$ & $(0.82)$ & $(0.66)$ & $(2.66)$ & $(2.70)$ & $(1.95)$ \\
\hline \multirow[t]{2}{*}{ Existence of road safety NGOs } & $1.49 * \star \star$ & $1.37 *$ & 1.25 & 1.27 & 0.59 & $0.56 *$ \\
\hline & $(0.28)$ & $(0.26)$ & $(0.25)$ & $(0.27)$ & $(0.20)$ & $(0.17)$ \\
\hline \multicolumn{7}{|l|}{ Coercion or Competition (ref. 'Importer vehicle country) a } \\
\hline \multirow[t]{2}{*}{ Importer-exporter vehicle country } & $1.99 *$ & $1.79 *$ & - & - & $6.58 *$ & $5.80 *$ \\
\hline & $(0.73)$ & $(0.61)$ & & & $(6.53)$ & $(5.74)$ \\
\hline \multirow[t]{2}{*}{ Exporter-importer vehicle country } & - & - & - & - & 4.75 & 4.55 \\
\hline & & & & & $(5.80)$ & $(5.54)$ \\
\hline \multirow[t]{2}{*}{ Exporter vehicle country } & 2.34 & $2.39 *$ & - & - & $8.73^{* \star}$ & $7.80 *$ \\
\hline & $(1.39)$ & $(1.20)$ & & & $(9.24)$ & $(8.21)$ \\
\hline \multicolumn{7}{|l|}{ Controls } \\
\hline \multirow[t]{2}{*}{ GDP per capita (In) } & 1.07 & 1.10 & $1.49 * * \star$ & $1.49 * * *$ & $1.44^{*}$ & 1.35 \\
\hline & $(0.13)$ & $(0.13)$ & $(0.17)$ & $(0.15)$ & $(0.29)$ & $(0.28)$ \\
\hline
\end{tabular}

RSA: Road Safety Agency; CRL: Child Restraint Legislation; DRL; Daytime Running Lights; LAC: Latin America and the Caribbean; AAUTPV: Agreement concerning the Adoption of Uniform Technical Prescriptions for Wheeled Vehicles, Equipment and Parts which can be fitted and/or be used on Wheeled Vehicles and the Conditions for Reciprocal Recognition of Approvals Granted on the Basis of these Prescriptions. Robust standard errors in parentheses. ${ }^{\star \star \star}$ significant at $1 \%$; ${ }^{\star \star}$ significant at $5 \%$; * significant at $10 \%$. All models adjusted for clustering at the region level. ${ }^{a}$ To facilitate the interpretation of the 'Type of importer-exporter vehicle country' variable we subdivided the 'Exporter-importer vehicle country' group into two: 'Importer-exporter vehicle country' and 'Exporter-importer vehicle country.' The latter represented countries in which their vehicle importation was 10 times higher than their vehicle exportation, and the former, in which country's importation was lower than 10 times higher than their vehicle exportation. 


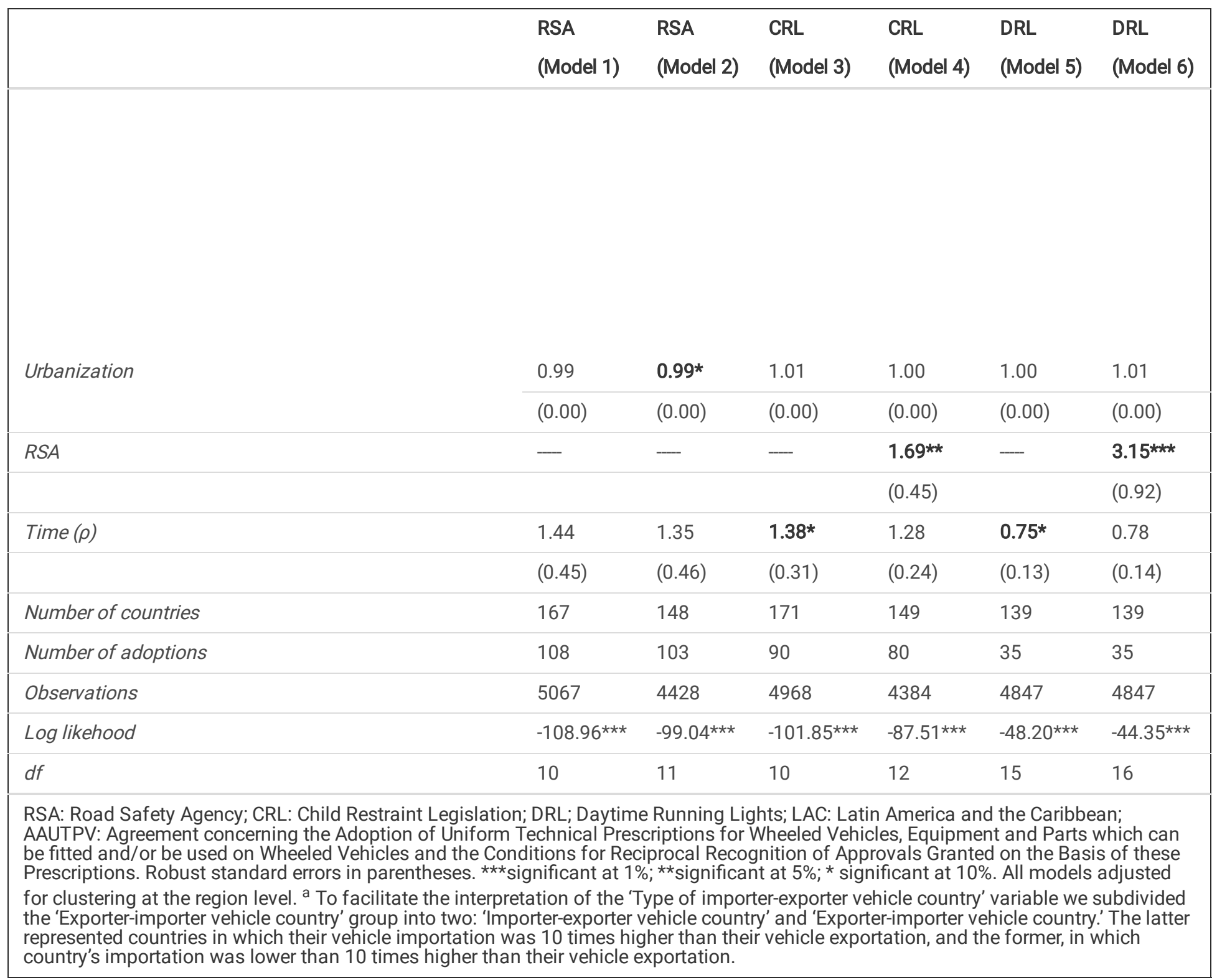

Table 2 reports the structural parameter $\rho$ for regional for Europe, and LAC. We observe that regional convergence occurs in these two regions for RSA and CRL, but not for DRL. However, the mechanisms that explain regional convergence are different for these two regions. In Europe (Models 7-9) one observes a complex array of mechanisms at play. First, the imitation/learning mechanism and presence in global agreements indeed accelerate the rate of adoption. That is, having participated in the Convention of Geneva, the WHO's road safety campaign and the presence of road safety NGOs had positive effects on RSA convergence. Second, after the creation of the European Transport Safety Council, the rate of adoption of RSA increases significantly. For CRL, only the presence of road safety NGOs increments its adoption. Interestingly, learning/imitation represented by the WHO's global campaign is the only mechanism of convergence which captures DRL adoption. Lastly, the presence of RSA as independent variable increases both CRL and DRL. For LAC, the only mechanism associated with the convergence of RSAs is WHO's campaign, and urbanization is the sole variable that is associated with CRL convergence.

Table 3 summarizes the mechanisms which facilitated convergence in each road safety policy in the world, Europe, and LAC respectively. With the exception of CRL in LAC, imitation/learning is present in each analyzed policy for each territory, and competition is associated with RSA in the world, and DRL in Europe. Evidence to accept the coercion mechanism is inconclusive. 
Table 2

Regional convergence of RSA, CRL and DRL in Europe and North America, and RSA, and CRL in Latin America and the Caribbean

\begin{tabular}{|c|c|c|c|c|c|}
\hline & Europe & & & LAC & \\
\hline & RSA & CRL & DRL & RSA & CRL \\
\hline & (Model 7) & (Model 8) & (Model 9) & (Model 10) & (Model 11) \\
\hline \multicolumn{6}{|l|}{ Global convergence } \\
\hline \multirow[t]{2}{*}{ Geneva Convention on Road Traffic } & $4.91 *$ & 0.88 & 0.88 & 2.11 & 0.65 \\
\hline & $(4.48)$ & $(0.62)$ & $(0.32)$ & $(3.18)$ & $(0.45)$ \\
\hline \multirow[t]{2}{*}{ AAUTPV } & 0.44 & 0.83 & 1.20 & - & - \\
\hline & $(0.79)$ & $(0.26)$ & $(0.40)$ & & \\
\hline \multicolumn{6}{|l|}{ Regional convergence } \\
\hline \multirow[t]{2}{*}{ Creation of the European Transport Safety Council } & $5.72 * \star$ & 1.18 & 0.47 & - & - \\
\hline & $(4.05)$ & $(0.36)$ & $(0.53)$ & & \\
\hline \multicolumn{6}{|l|}{ Unintended convergence } \\
\hline \multicolumn{6}{|l|}{ General national circumstances } \\
\hline \multirow[t]{2}{*}{ Population (In) } & 1.15 & 0.80 & $0.00 * \star \star *$ & $0.82 *$ & 0.87 \\
\hline & $(1.19)$ & $(0.11)$ & $(0.00)$ & $(0.72)$ & $(0.19)$ \\
\hline \multirow[t]{2}{*}{ Political violence (In) } & 1.03 & 1.06 & 0.78 & 1.16 & 0.86 \\
\hline & $(2.13)$ & $(0.29)$ & $(-0.88)$ & $(0.36)$ & $(0.66)$ \\
\hline \multirow{2}{*}{ Average yearly total number of hours of bright sunshine } & - & - & 1.37 & & \\
\hline & & & $(0.41)$ & & \\
\hline \multicolumn{6}{|l|}{ Mechanisms of diffusion } \\
\hline \multicolumn{6}{|l|}{ Imitation/learning } \\
\hline \multirow[t]{2}{*}{ World Health Organization road safety global campaign } & $1.92^{\star *}$ & 1.411 & $5.85^{* *}$ & $1.96 *$ & $0.37 * \star \star$ \\
\hline & $(0.65)$ & $(0.84)$ & $(4.53)$ & $(2.23)$ & $(0.09)$ \\
\hline \multirow[t]{2}{*}{ Existence of road safety NGOs } & $2.79 * *$ & $1.54 * \star$ & 0.45 & 1.16 & 0.62 \\
\hline & $(1.29)$ & $(0.31)$ & $(0.22)$ & $(0.44)$ & $(0.19)$ \\
\hline \multicolumn{6}{|l|}{ Coercion or Competition (ref. 'Importer vehicle country) a } \\
\hline \multirow[t]{2}{*}{ Importer-exporter vehicle country } & 0.48 & - & & - & - \\
\hline & $(0.47)$ & & & & \\
\hline \multirow[t]{2}{*}{ Exporter vehicle country } & 1.29 & - & 1.97 & 105.88 & - \\
\hline & $(1.12)$ & & $(1.07)$ & $(322.66)$ & \\
\hline \multicolumn{6}{|l|}{ Controls } \\
\hline \multirow[t]{2}{*}{ GDP per capita (In) } & 0.67 & $2.03^{* * *}$ & $1.30 * * *$ & 0.60 & 1.04 \\
\hline & $(0.20)$ & $(0.34)$ & $(0.12)$ & $(0.36)$ & $(0.05)$ \\
\hline
\end{tabular}

RSA: Road Safety Agency; CRL: Child Restraint Legislation; DRL; Daytime Running Lights; LAC: Latin America and the Caribbean; AAUTPV: Agreement concerning the Adoption of Uniform Technical Prescriptions for Wheeled Vehicles, Equipment and Parts which can be fitted and/or be used on Wheeled Vehicles and the Conditions for Reciprocal Recognition of Approvals Granted on the Basis of these Prescriptions. Robust standard errors in parentheses. ***significant at $1 \%$; **significant at $5 \%$; *significant at $10 \%$. All models adjusted for clustering at the region level. ${ }^{a}$ For the Model 10 in Latin America and the Caribbean, the reference category is a combination of the categories 'Importer vehicle country' and 'Importer-exporter vehicle country.' a No 'Importer vehicles country' was registered in this region. 


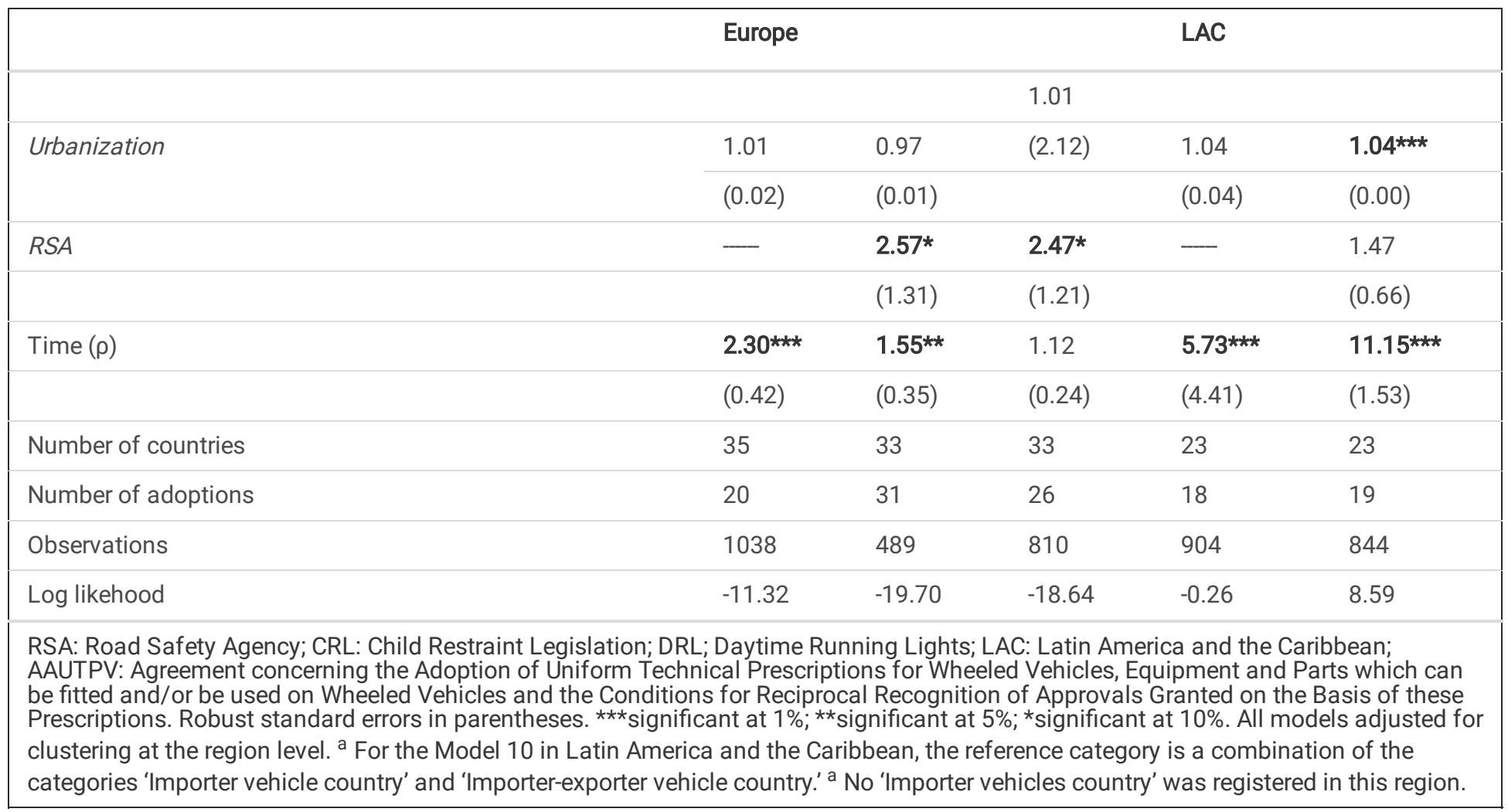

Table 3

Type of convergence outcomes and mechanisms of diffusion by RSA, CRL and DRL

\begin{tabular}{|c|c|c|c|c|c|}
\hline $\begin{array}{l}\text { Road safety } \\
\text { policy }\end{array}$ & Territory & $\begin{array}{l}\text { Type of convergence } \\
\text { outcomes }\end{array}$ & $\begin{array}{l}\text { International } \\
\text { agreement }\end{array}$ & $\begin{array}{l}\text { Mechanisms of } \\
\text { diffusion }\end{array}$ & Local dynamics \\
\hline \multirow[t]{4}{*}{ RSA } & World & Unintended convergence & None & Imitation/learning & Political violence \\
\hline & & & & Competition & Population \\
\hline & Europe & Regional convergence & Geneva Convention & Imitation/learning & No \\
\hline & LAC & Regional convergence & None & Imitation/learning & Population \\
\hline \multirow[t]{4}{*}{ CRL } & World & Global convergence & AAUTPV & Imitation/learning & Political violence \\
\hline & & & & & $\begin{array}{l}\text { Road Safety } \\
\text { Agencies }\end{array}$ \\
\hline & Europe & Regional convergence & None & Imitation/learning & $\begin{array}{l}\text { Road Safety } \\
\text { Agencies }\end{array}$ \\
\hline & LAC & Regional convergence & None & No & Urbanization \\
\hline \multirow[t]{5}{*}{ DRL } & World & Unintended convergence & AAUTPV & Imitation/learning & Population \\
\hline & & & & Competition & $\begin{array}{l}\text { Road Safety } \\
\text { Agencies }\end{array}$ \\
\hline & Europe & Unintended convergence & None & Imitation/learning & Population \\
\hline & & & & & Political violence \\
\hline & & & & & $\begin{array}{l}\text { Road Safety } \\
\text { Agencies }\end{array}$ \\
\hline \multicolumn{6}{|c|}{$\begin{array}{l}\text { RSA: Road Safety Agency; CRL: Child Restraint Legislation; DRL; Daytime Running Lights; LAC: Latin America and the Caribbean; } \\
\text { AAUTPV: Agreement concerning the Adoption of Uniform Technical Prescriptions for Wheeled Vehicles, Equipment and Parts which can } \\
\text { be fitted and/or be used on Wheeled Vehicles and the Conditions for Reciprocal Recognition of Approvals Granted on the Basis of these } \\
\text { Prescriptions. }\end{array}$} \\
\hline
\end{tabular}

\section{Discussion And Conclusion}


Our analyses show that there were different types of convergence with respect to the three road safety policies examined-which emerged approximately at the same time and have been promoted by recognized international actors such as the WHO and the WB. Nevertheless, unlike what the global convergence thesis predicts, the shape of their convergence varies. We thus conclude that the nature of convergence depends on regional arrangements, type of international actors involved and national dynamics, rather than exclusively on global forces spreading nation-states' scripts homogeneously across the world.

We also found that effects of global forces are facilitated by regional efforts and that spreading of policies can indeed overcome national dynamics. Thus, for the case of RSA in LAC, we observe that the WHO's global campaign increased the rate of adoption of these policies respectively, operating through the functioning of specific working groups. In LAC, several international organizations, such as the Pan American Health Organization, the Economic Commission of Latin America and the Caribbean, and the Inter-American Development Bank, in coordination with national representatives, jointly developed a regional approach for the road safety challenge over the past 20 years. They have, through different instruments or forums, recognized the importance of RSAs (Nazif and Pérez, 2013).

The puzzle of why DRL did not globally converge deserves a lengthier discussion. While the evidence indicates that the learning/imitation mechanism is adequate to understand the convergence on this policy throughout Europe, we still need to account for, at least indirectly, why it did not diffuse to other regions. This is important considering that that this measure is not new and scientific evidence has been used to document its effectiveness. Three complementary explanations can be proposed: First, this measure may not have been championed to the extent that the cases of RSA or CRL have. There has been strong historical support for the adoption of CRL from the pediatric community (Durbin et al., 2015) and the WB has been a key organization in promoting RSAs. And while the WHO lobbied for DRL (Bliss and Breen, 2012), in the past ten years this organization has focused on other measures more prominently (World Health Organization, 2013). Second, as other scholars have suggested (Simmons, Dobbin and Garrett, 2008) examining the role of the USA can indeed provide insights when studying the convergence of policies. While the USA created its road safety agency (National Highway Traffic Safety Administration (NHTSA)) in 1966, and the last US state enacted CRL in 1983, DRL remains not compulsory. In this regard, it is important to notice that representatives of the automobile industry within the USA have had a prominent role in attempting to disseminate this policy in this country; but NHTSA has resisted its enactment. In 1993 and 2001, representatives of General Motors formally requested, on the basis of two studies regarding the effectiveness of this measure, the introduction of this device to be mandatory. On both occasions, NHTSA questioned the efficacy of this measure. In 2009, NHTSA concluded that "the agency ... has been unable to determine if there are any demonstrable safety benefits associated with DRLs, and therefore leaving them as a manufacturer option is the best outcome" (National Highway Traffic Safety Administration, 2009). Following this, the USA's road safety prominence may have influenced most countries in not adopting DRL. The case of the automobile industry promoting DRL in the USA indeed questions the notion that this industry would resist the introduction of safety devices. Nevertheless, this example reinforces what we found in the models, that is, the automobile industry may not be a homogenous group across countries. Lastly, in juxtaposition with this second explanation, we also suspect that lacking an institution, that resembles the European Transport Safety Council, in each region, can provide with an explanation of why DRL has not spread globally. The European Transport Safety Council is composed of a formal network of academics, researchers, and government representatives, who congregate formally and regularly with the aim to debate and analyze road safety measures. Lacking this institutional structure may make the global diffusion of contested road safety policies at the regional level more challenging, since more sustained efforts may be needed to promote them. The official position of this council, after the European Union requested a public consultation for considering the approval of DRL, was to mandate "equipment of low-energy consumption dedicated DRL on all new vehicles accompanied by a measure mandating the use of dipped headlights on existing vehicles" (European Transport Safety Council, 2006). In Europe, this position was endorsed by three research centers, the Organisation for Applied Scientific Research, the Institute for Road Safety Research, and the Institute of Transport Economics, which conducted research to assess the effectiveness of this measure.

In terms of the mechanisms studied, we observe learning/imitation and competition to be adequate to understand road safety policy convergence. Relatively speaking, competition is not observed, denoting either limitation on how we operationalize it or simply lacks generalizability. It is important to highlight that, conceptually, mechanisms do not have to compete with each other. Rather, it seems that if one is interested in understanding how convergence occurs, one is better off suggesting that mechanisms may capture different stages and/or different trajectories of these processes. For instance, we notice that in Europe the spreading and convergence of RSAs is facilitated by both the formation of early networks, and national dynamics which signalled the emergence of a public concern.

Three limitations of the current study should be mentioned. First, there is considerable variation on how we defined RSA, DRL and CRL, thus our analyses should be taken with caution because our operationalization ultimately conflates restrictive with more flexible classifications. We suggest taking our results as signals that lead us to understand how global policies may converge. In this regard it is also important to consider only provisionally the built dataset since the quality of information by country may vary and therefore this could have effects in some estimators. Second, because this study considers only cases in which each policy was first introduced, subsequent reforms in each of these policies may also play a role in other diffusion and convergence processes among each of these policies or other road safety policies.

Page 12/17 
International efforts such as the global road safety campaign may have influenced subsequent changes. For instance, in Canada CRL were implemented before the global campaign (Fridman et al., 2018) however after this campaign, stricter regulations have also been observed in this country. Relatedly while we suggest specific first dates of when policies were enacted, there may have been differences between these dates and when policies took effect, which in turn may be biasing the results. Finally, because high traffic fatality rates could have been associated with the adoption of these policies, this variable should have been introduced. Nevertheless, because we controlled for population, GDP per capita, and urbanization these could be taken as proxies for traffic fatality rates.

In conclusion, our analysis suggests that future studies on policy convergence should consider regional and national dynamics more consistently as well as conduct more systematic tests of falsification by contrasting the implementation of different policies simultaneously. Doing so will lead to more nuanced research findings. By highlighting differences in the diffusion of distinct policies, we showed that convergence indeed takes different shapes: global, regional and unintended. Lastly, we were also able to tease out some of the mechanisms at play to describe how convergence may differ regionally and globally.

\section{Declarations}

\section{Declaration of competing interest}

The authors declare that they have no known competing financial interests or personal relationships that could have appeared to influence the work reported in this paper.

\section{References}

1. Ameratunga, S., Hijar, M. and Norton, R. (2006) 'Road-traffic injuries: confronting disparities to address a global-health problem', The Lancet, 367(9521), pp. 1533-1540. doi:10.1016/S0140-6736(06)68654-6.

2. Bliss, T. and Breen, J. (2012) 'Meeting the management challenges of the Decade of Action for Road Safety', IATSS research, 35(2), pp. 48-55.

3. Brandon Tuma, N. (1984) Social Dynamics Models and Methods - 1st Edition. Academic Press. Available at: https://www.elsevier.com/books/social-dynamics-models-and-methods/tuma/978-0-12-703670-0 (Accessed: 14 June 2021).

4. Brooks, S.M. (2005) 'Interdependent and domestic foundations of policy change: The diffusion of pension privatization around the world', International Studies Quarterly, 49(2), pp. 273-294.

5. Central IntelligenceAgency (2011) The World Factbook 2011. U.S. Government Printing Office.

6. Cleves, M. et al. (2008) An Introduction to Survival Analysis Using Stata, Second Edition. Stata Press.

7. Cole, W.M. (2012) 'Human Rights as Myth and Ceremony? Reevaluating the Effectiveness of Human Rights Treaties, 1981-2007', American Journal of Sociology, 117(4), pp. 1131-1171. doi:10.1086/662706.

8. Dobbin, Simmons, B. and Garrett, G. (2007) 'The Global Diffusion of Public Policies: Social Construction, Coercion, Competition, or Learning?', Annual Review of Sociology, 33.

9. Drezner, D.W. (2001) 'Globalization and Policy Convergence', International Studies Review, 3(1), pp. 53-78.

10. Durbin, D.R. et al. (2015) 'Rear seat safety: Variation in protection by occupant, crash and vehicle characteristics', Accident; Analysis and Prevention, 80, pp. 185-192. doi:10.1016/j.aap.2015.04.006.

11. Elvik, R. et al. (eds) (2009) The Handbook of Road Safety Measures. Emerald Group Publishing Limited. doi:10.1108/9781848552517.

12. Elvik, R. (2013) 'Can a road safety measure be both effective and ineffective at the same time? A game-theoretic model of the effects of daytime running lights', Accident Analysis \& Prevention, 59, pp. 394-398. doi:10.1016/j.aap.2013.06.039.

13. European Transport Safety Council (2006) 'Public consultation on "Saving lives with daytime running lights (DRL)"'.

14. Flannigan, S.A. and Khayesi, M. (2021) 'Content analysis of reported activities of the United Nations Road Safety Collaboration Members during the Decade of Action for Road Safety 2011-2020', BMJ Open, 11(3), p. e042409. doi:10.1136/bmjopen-2020-042409.

15. Frank, D.J., Camp, B.J. and Boutcher, S.A. (2010) 'Worldwide Trends in the Criminal Regulation of Sex, 1945 to 2005 ', American Sociological Review, 75(6), pp. 867-893. doi:10.1177/0003122410388493.

16. Fridman, L. et al. (2018) 'Childhood road traffic injuries in Canada - a provincial comparison of transport injury rates over time', $B M C$ Public Health, 18(1), p. 1348. doi:10.1186/s12889-018-6269-9.

17. Gilardi, F., Füglister, K. and Luyet, S. (2009) 'Learning From Others: The Diffusion of Hospital Financing Reforms in OECD Countries', Comparative Political Studies, 42(4), pp. 549-573. doi:10.1177/0010414008327428.

18. Global Alliance for NGOs for road safety (2020) 'Membership'. Available at: http://www.roadsafetyngos.org/about/about-us/history/. 
19. Hafner-Burton, E.M. and Tsutsui, K. (2005) 'Human Rights in a Globalizing World: The Paradox of Empty Promises', American Journal of Sociology, 110(5), pp. 1373-1411. doi:10.1086/428442.

20. Harvey, D. (1989) The Condition of Postmodernity: An Enquiry into the Origins of Cultural Change. Wiley. Available at: https://www.wiley.com/en-gb/The+Condition+of+Postmodernity\%3A+An+Enquiry+into+the+Origins+of+Cultural+Change-p9780631162940 (Accessed: 14 June 2021).

21. Hyder, A.A. et al. (2017) 'Monitoring the Decade of Action for Global Road Safety 2011-2020: An update', Global Public Health, 12(12), pp. 1492-1505. doi:10.1080/17441692.2016.1169306.

22. Iriart, C., Merhy, E.E. and Waitzkin, H. (2001) 'Managed care in Latin America: the new common sense in health policy reform', Social Science \& Medicine, 52(8), pp. 1243-1253.

23. Jenkins, S.P. (2005) Survival Analysis. Institute for Social and Economic Research, University of Essex. UK. Available at: https://citeseerx.ist.psu.edu/viewdoc/download?doi=10.1.1.176.7572\&rep=rep1\&type=pdf (Accessed: 15 June 2021).

24. Knight, I. et al. (2007) 'Daytime Running Lights (DRL): a review of the reports from the European Commission', PUBLISHED PROJECT REPORT PPR170 [Preprint]. Available at: https://trid.trb.org/view/803972 (Accessed: 14 June 2021).

25. Kogut, B. and Macpherson, J.M. (2008) The decision to privatize: economists and the construction of ideas and policies, The Global Diffusion of Markets and Democracy. Cambridge University Press. doi:10.1017/CB09780511755941.003.

26. Kogut, B. and Macpherson, J.M. (2011) 'The mobility of economists and the diffusion of policy ideas: The influence of economics on national policies', Research Policy, 40(10), pp. 1307-1320. doi:10.1016/j.respol.2011.06.008.

27. Koo, J.-W. and Ramirez, F.O. (2009) 'National incorporation of global human rights: Worldwide expansion of national human rights institutions, 1966-2004', Social Forces, 87(3), pp. 1321-1353.

28. Koornstra, M. (1993) Daytime running lights: Its safety evidence revisited. / SWOV. Available at: https://www.swov.nl/publicatie/daytimerunning-lights-its-safety-evidence-revisited (Accessed: 14 June 2021).

29. Kopits, E. and Cropper, M. (2003) Traffic Fatalities and Economic Growth. The World Bank (Policy Research Working Papers). doi:10.1596/1813-9450-3035.

30. Lee, C.K. and Strang, D. (2006) 'The International Diffusion of Public-Sector Downsizing: Network Emulation and Theory-Driven Learning', International Organization, 60(4), pp. 883-909. doi:10.1017/S0020818306060292.

31. Lozano, R. et al. (2012) 'Global and regional mortality from 235 causes of death for 20 age groups in 1990 and 2010 : a systematic analysis for the Global Burden of Disease Study 2010', The Lancet, 380(9859), pp. 2095-2128. doi:10.1016/S0140-6736(12)61728-0.

32. Luke, N. and Cotts Watkins, S. (2002) Reactions of Developing-Country Elites to International Population Policy - Luke - 2002 Population and Development Review - Wiley Online Library. Available at: https://onlinelibrary.wiley.com/doi/abs/10.1111/j.17284457.2002.00707.x (Accessed: 14 June 2021).

33. Marsh, D. and Sharman, J.C. (2009) 'Policy diffusion and policy transfer', Policy Studies, 30(3), pp. $269-288$. doi:10.1080/01442870902863851.

34. Marshall, M. (2021) 'Polity V: Political Regime Characteristics and Transitions, 1800-2018 - Data and Statistical Services'. Available at: https://dss.princeton.edu/catalog/resource93 (Accessed: 14 June 2021).

35. Martinneli, A. (2005) 'From World System to World Society?', Journal of World-Systems Research, pp. 241-260. doi:10.5195/jwsr.2005.389.

36. Meyer, J.W. et al. (1997) 'World Society and the Nation-State', American Journal of Sociology, 103(1), pp. 144-181. doi:10.1086/231174.

37. Mohan, D. and Roberts, I. (2001) 'Global road safety and the contribution of big business', BMJ: British Medical Journal, 323(7314), p. 648.

38. Murillo, M.V. and Martínez-Gallardo, C. (2007) ‘Political Competition and Policy Adoption: Market Reforms in Latin American Public Utilities', American Journal of Political Science, 51(1), pp. 120-139.

39. National Highway Traffic Safety Administration (2009) Federal Motor Vehicle Safety Standard No. 108; Lamp, Reflective Devices and Associated Equipment, Code of Federal Regulations Title 49 - Transportation. Available at: https://www.federalregister.gov/documents/2009/06/29/E9-15314/federal-motor-vehicle-safety-standard-no-108-lamp-reflectivedevices-and-associated-equipment (Accessed: 14 June 2021).

40. Nazif, J.I. and Pérez, G. (2013) 'Road Safety in Latin America and the Caribbean: Recent Performance and Future Challenges'. Available at: https://repositorio.cepal.org/handle/11362/36293 (Accessed: 14 June 2021).

41. Nazif-Muñoz, J.I. (2015) 'Did Child Restraint Laws Globally Converge? Examining 40 Years of Policy Diffusion', Traffic Injury Prevention, 16 Suppl 2, pp. S32-40. doi:10.1080/15389588.2015.1061661. 
42. Organization (WMO), W.M. and World Meteorological Organization (WMO) (2018) Guide to Instruments and Methods of Observation. 2018 Edition. Geneva: WMO (WMO).

43. Pegram, T. (2010) 'Diffusion Across Political Systems: The Global Spread of National Human Rights Institutions', Human Rights Quarterly, 32(3), pp. 729-760.

44. Roberts, I. (2007) 'Formula One and global road safety', Journal of the Royal Society of Medicine, 100(8), pp. 360-362.

45. Roberts, I., Wentz, R. and Edwards, P. (2006) 'Car manufacturers and global road safety: a word frequency analysis of road safety documents', Injury Prevention, 12(5), pp. 320-322. doi:10.1136/ip.2006.012849.

46. Rompuy, P.V. (2021) 'Does subnational tax autonomy promote regional convergence? Evidence from OECD countries, 1995-2011', Regional Studies, 55(2), pp. 234-244. doi:10.1080/00343404.2020.1800623.

47. Rosenberg, M.L. et al. (2010) Real Collaboration: What It Takes for Global Health to Succeed.

48. Samferdselsdepartementet (1964) Law on roads (veglova) - Lovdata. Available at: https://lovdata.no/dokument/NL/lov/1963-06-2123\#KAPITTEL_2 (Accessed: 29 September 2021).

49. Sharma, B.R. (2008) 'Road traffic injuries: a major global public health crisis', Public Health, 122(12), pp. 1399-1406. doi:10.1016/j.puhe.2008.06.009.

50. Shor, E. (2008) 'Conflict, Terrorism, and the Socialization of Human Rights Norms: The Spiral Model Revisited', Social Problems, 55(1), pp. 117-138. doi:10.1525/sp.2008.55.1.117.

51. Shor, E. et al. (2014) 'Terrorism and state repression of human rights: a cross-national time-series analysis', International Journal of Comparative Sociology, 55(4), pp. 294-317.

52. Simmons, B.A., Dobbin, F. and Garrett, G. (2008) Introduction: The Diffusion of Liberalization. Cambridge University Press. doi:10.1017/CB09780511755941.001.

53. Simmons, B.A. and Elkins, Z. (2004) 'The Globalization of Liberalization: Policy Diffusion in the International Political Economy', American Political Science Review, 98(1), pp. 171-189. doi:10.1017/S0003055404001078.

54. Skrede Gleditsch, K. and Ward, M.D. (2008) 'Diffusion and the spread of democratic institutions', in Simmons, B.A., Dobbin, F., and Garrett, G. (eds) The Global Diffusion of Markets and Democracy. Cambridge: Cambridge University Press, pp. 261-302. doi:10.1017/CB09780511755941.007.

55. STRANG, D. (1991) 'Adding Social Structure to Diffusion Models: An Event History Framework', Sociological Methods \& Research, 19(3), pp. 324-353. doi:10.1177/0049124191019003003.

56. Strang, D. (1994) 'British and French political institutions and the patterning of decolonization', in Hicks, A.M. and Janoski, T. (eds) The Comparative Political Economy of the Welfare State. Cambridge: Cambridge University Press (Cambridge Studies in Comparative Politics), pp. 278-296. doi:10.1017/СB09781139174053.012.

57. Strang, D. and Meyer, J.W. (1993) 'Institutional Conditions for Diffusion', Theory and Society, 22(4), pp. 487-511.

58. Sze, N.N., Wong, S.C. and Lee, C.Y. (2014) 'The likelihood of achieving quantified road safety targets: A binary logistic regression model for possible factors', Accident Analysis \& Prevention, 73, pp. 242-251. doi:10.1016/j.aap.2014.09.012.

59. The Norwegian Public Roads Administration (2021) Event history - State Administration Database - NSD. Available at: https://www.nsd.no/polsys/data/en/forvaltning/enhet/8601/endringshistorie (Accessed: 29 September 2021).

60. True, J. and Mintrom, M. (2001) 'Transnational Networks and Policy Diffusion: The Case of Gender Mainstreaming', International Studies Quarterly, 45(1), pp. 27-57.

61. United Nations (1995) 'Agreement concerning the Adoption of Uniform Technical Prescriptions for Wheeled Vehicles, Equipment and Parts Which Can Be Fitted and/or Be Used on Wheeled Vehicles and the Conditions for Reciprocal Recognition of Approvals Granted on the Basis of These Prescriptions.' Available at: https://digitallibrary.un.org/record/227567 (Accessed: 14 June 2021).

62. United Nations (2016) Transforming our world: the 2030 agenda for sustainable development, United Nations, A/RES/70/1. Available at: https://sustainabledevelopment.un.org/content/documents/21252030\%20Agenda\%20for\%20Sustainable\%20Development\%20web.pdf (Accessed: 28 July 2021).

63. United Nations (2020) 'Commodity Trade Statistics Database'. Available at: https://comtrade.un.org/ (Accessed: 15 June 2021).

64. United Nations (2021) United Nations Road Safety Week. Available at: https://www.who.int/teams/social-determinants-of-health/safetyand-mobility/united-nations-road-safety-week (Accessed: 29 July 2021).

65. Wallerstein, I. (1974) 'The Rise and Future Demise of the World Capitalist System: Concepts for Comparative Analysis', Comparative Studies in Society and History, 16(4), pp. 387-415. doi:10.1017/S0010417500007520.

66. Wallerstein, I. (1979) The Capitalist World-Economy.

Page 15/17 
67. Wallerstein, I. (2004) World-Systems Analysis: An Introduction. Durham. Available at: https://www.amazon.com/World-SystemsAnalysis-Introduction-Immanuel-Wallerstein/dp/0822334429 (Accessed: 14 June 2021).

68. Wallerstein, I. (2011) The Modern World-System I: Capitalist Agriculture and the Origins of the European World-Economy in the Sixteenth Century.

69. Weyland, K. (2005) 'Theories of Policy Diffusion Lessons from Latin American Pension Reform', World Politics, 57(2), pp. $262-295$. doi:10.1353/wp.2005.0019.

70. Wipfli, H.L., Fujimoto, K. and Valente, T.W. (2010) 'Global tobacco control diffusion: the case of the framework convention on tobacco control', American Journal of Public Health, 100(7), pp. 1260-1266. doi:10.2105/AJPH.2009.167833.

71. World Bank (2020) World Development Indicators / DataBank. Available at: https://databank.worldbank.org/source/world-developmentindicators (Accessed: 14 June 2021).

72. World Health Organization (2004) World report on road traffic injury prevention. Available at: https://www.who.int/publications-detailredirect/world-report-on-road-traffic-injury-prevention (Accessed: 14 June 2021).

73. World Health Organization (2010) Global status report on road safety: time for action. World Health Organization.

74. World Health Organization (2013) Global status report on road safety. World Health Organization.

75. World Health Organization (2019) Global status report on alcohol and health 2018. Available at: https://www.who.int/publicationsdetail-redirect/9789241565639 (Accessed: 27 May 2021).

76. Wotipka, C.M. and Ramirez, F.O. (2008) 'World society and human rights: an event history analysis of the Convention on the Elimination of All Forms of Discrimination against Women', in Simmons, B.A., Dobbin, F., and Garrett, G. (eds) The Global Diffusion of Markets and Democracy. Cambridge: Cambridge University Press, pp. 303-343. doi:10.1017/CB09780511755941.008.

77. Wotipka, C.M. and Tsutsui, K. (2008) 'Global Human Rights and State Sovereignty: State Ratification of International Human Rights Treaties, 1965-2001', Sociological Forum, 23(4), pp. 724-754.

78. Zeveleva, O. and Nazif-Munoz, J.I. (2021) 'COVID-19 and European carcerality: Do national prison policies converge when faced with a pandemic?', Punishment \& Society, p. 14624745211002012. doi:10.1177/14624745211002011.

\section{Figures}


Figure 1 Number of National Road Safety Policies, 1957 to 2015

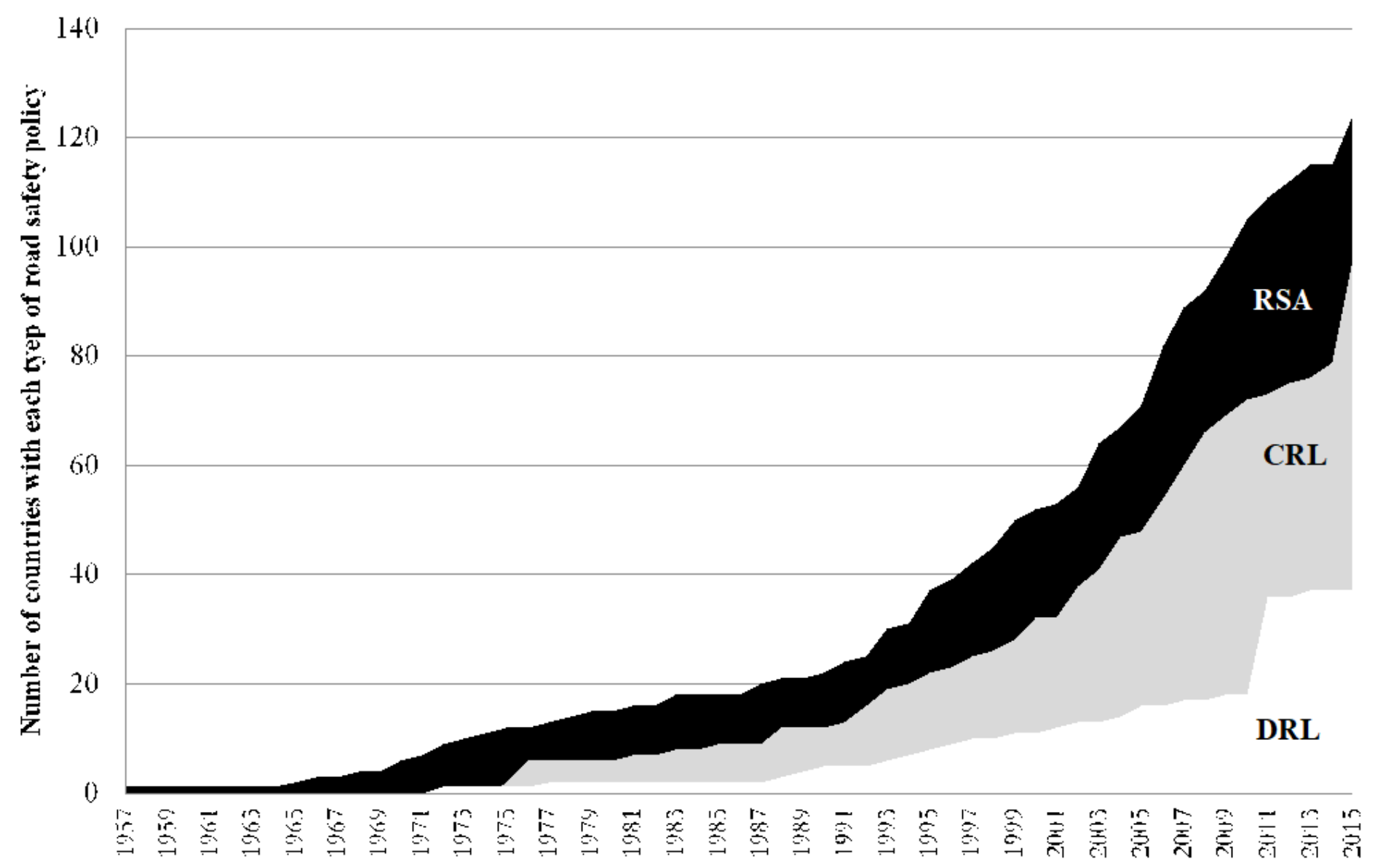

RSA: Road Safety Agencies; CRL: Child Restraint Laws; DRL: Daytime Running Lights.

Figure 1

Number of National Road Safety Policies, 1957 to 2015

\section{Supplementary Files}

This is a list of supplementary files associated with this preprint. Click to download.

- SupplementaryMaterialSS.C.H.docx 